Brit. J. vener. Dis. (1956), 32, 209.

\title{
INTRADERMAL TESTS IN THE DIAGNOSIS OF LYMPHOGRANULOMA VENEREUM*
}

\author{
BY \\ A. J. KING, $\dagger$ C. F. BARWELL, AND R. D. CATTERALL \\ From the Department of Venereal Diseases (Whitechapel Clinic) and the Department of Bacteriology, The London \\ Hospital
}

\section{Frei Antigen}

Until the beginning of the last decade the intradermal test of Frei (1925) was the only method by which the clinical diagnosis of lymphogranuloma venereum could be confirmed. His antigen consisted of bacteriologically sterile pus obtained from an unruptured bubo of a patient suffering from the disease. Fresh pus was used, diluted 1 part in 5 with normal saline, or, as suggested by Grace (1934), pus dried from the frozen state, diluted 1 part in 50 . The latter was stated to retain potency for a considerable period-as long as three years, according to Hanschell (1938). The antigen was sterilized by heating at $60^{\circ} \mathrm{C}$. for 2 hours on one day and for 1 hour on the next. One-tenth of a millilitre was injected intradermally and the probability of present or previous infection was indicated by the appearance, after 48 to 72 hours, of an inflammatory papule, 6 millimetres or more in diameter, at the site of injection.

The danger of contamination of this preparation was considerable, for it was prepared without an antiseptic and made an excellent culture medium. According to Frei (1938) the most common source of error with the test was contamination of the antigen with living or dead bacteria, resulting in local non-specific inflammatory reactions. On the other hand, a negative result was not to be considered as proof that the patient had not suffered from lymphogranulomatous infection. The test might be falsely negative if the antigen was overheated or otherwise improperly prepared. For the result to be accepted as positive, it was essential that the papule should be of sufficient size; erythema

* Received for publication June 23, 1956.

t Presidential Address to the M.S.S.V.D., April 27, 1956. alone was of no significance. Frei (1939) said that other disadvantages of this antigen lay in

(1) the difficulty of finding suitable sources of pus, namely patients with unruptured buboes free from bacterial infection and without evidence of other venereal disease;

(2) the varying potency of pus obtained from individual patients;

(3) the variable periods for which potency was retained.

However, most workers agreed that the original Frei test was specific, in so far as a negative test was generally held to exclude present or past infection. Franchi (1939) and Smith (1940) studied microscopic changes at the sites of positive reaction to the Frei test and described a picture which was quite different from that produced by bacterial antigens, findings which seemed to confirm the specific nature of the test. Robinson (1940) doubted the specificity of the test because he found many positive results in patients without history or clinical evidence of lymphogranulomatous infection, and especially in patients suffering from syphilis. For this reason he believed that syphilis caused false positive results. It seemed to him that if the test was specific, the disease must be acquired frequently without symptoms and that sensitivity to the antigen must persist for years, or ior a lifetime, without manifest disease. Brandt and Torpin (1940) also found a considerable number of positive responses to the Frei test in patients without history or symptoms of lymphogranuloma venereum, but they rejected the view that false positive tests resulted from non-specific factors. They believed that such factors could produce reactions, but not reactions of convincing strength. They thought that positive Frei tests probably 
indicated past lymphogranulomatous infection because these results, though lacking clinical confirmation, were commonly found in patients who were promiscuous and suffered from other venereal diseases, particularly syphilis and granuloma inguinale.

\section{Animal Antigens}

Antigens obtained from animal tissue were first used for this test by Hellerström and Wassen (1931) who produced infection of the brains of monkeys and obtained antigen from this source. Wassen (1933) used infected mouse brain as a source of antigenic material and reported successful results, although there were some false positive reactions and some reactions were obtained with uninfected mouse brain, both in infected and non-infected patients. Grace and Suskind (1936, a, b) used mouse brain antigen and, in contrast with the unsatisfactory results which had been reported by other observers, claimed that there were no false positive reactions. They found that reactions were more intense and just as specific as those produced by antigens from human sources. The preparation retained its potency for at least 8 months and it could also be preserved by drying in vacuo from the frozen state. After intradermal injection a positive reaction was indicated by the appearance, after 48 to 72 hours, of a papule with a diameter of $7 \mathrm{~mm}$. or larger. Reactions with a control antigen consisting of normal mouse brain were insignificant. Other workers obtained variable results with this antigen. Binkley and Love (1938) used mouse brain antigen in testing 88 patients who had no signs of lymphogranulomatous infection and in whom intradermal tests with reliable human antigen were negative. Tests with the mouse brain antigen were positive after 48 hours in 64 cases (72.7 per cent.). In 56 of these cases, however, the test was also positive with suspensions of normal mouse brain. Wawersig (1939) obtained some positive reactions with normal mouse brain but these were less persistent than those which resulted from the infected material. Périn, Duperrat, and Lafontaine (1946) found mouse brain antigen to be specific and reactions were strong and clear-cut. Rake, Shaffer, Grace, McKee, and Jones (1941) found the mouse brain antigen to be useful and effective, but that it suffered from two main disadvantages:

(a) The occurrence of non-specific reactions which, however, should be detected if control 'tests with normal mouse brain were always included;

(b) The fact that the concentration of the virus in the brains of diseased mice was not high. In consequence, tests might appear doubtful, or even negative, in patients who, although they suffered from the specific infection, did not show strong reactions to such antigens.

In their experience, induced hypersensitivity to the animal protein content of this antigen occurred only very rarely.

\section{Yolk Sac Antigen}

The success of Rake, McKee, and Shaffer (1940) in growing the virus in large amount in the cells of the yolk sac of the developing chick embryo, and in separating the virus from much of the yolk and tissue components by differential centrifugation, led to the production from this source by Grace, Rake, and Shaffer (1940) of an antigen which was produced commercially and given the name Lygranum. The test was performed in the usual way with $0.1 \mathrm{ml}$. antigen, and results were read either 48 or 72 hours after inoculation. In every instance control inoculations were performed with material prepared from uninfected yolk sacs. In reading the reactions, attention was paid only to the central papule or indurated area. The surrounding erythematous zone was considered to be without diagnostic value. Rake and others (1941) found that patients suffering from lymphogranuloma venereum developed, in each case, a flat indurated papule, with or without central necrosis and surrounding erythema, and measuring at least $6 \mathrm{~mm}$. in its smallest diameter. The reaction reached its maximum intensity 48 to 72 hours after inoculation. The height of the papule and the surrounding erythema both tended to be less than those produced in the same individuals with mouse brain antigens. Reactions with suspensions of normal yolk sac were rare in normal people or in those suffering from lymphogranuloma venereum. Nevertheless, hypersensitivity to yolk sac material was found in less than 1 per cent. of those tested, and resulted in the development of indurated areas of equal size at the sites of injection of both antigen and control. The antigen was superior to mouse brain antigen in sensitivity and specificity. With yolk sac antigen, positive tests were obtained in 98.6 per cent. of 65 patients with clinical evidence of lymphogranuloma venereum as compared with $79 \cdot 1$ per cent. of positives with mouse brain antigen in the same cases. Positive reactions with Lygranum in patients who gave negative reactions with mouse brain antigen appeared to be specific reactions because the specificity was confirmed by clinical findings and by complement-fixation tests in many of the cases. Sulkin (1941) obtained similar results with 42 patients suffering from lymphogranuloma venereum. Axelrod (1942) found that this antigen gave results which conformed to the histories or clinical findings in a large percentage of cases. However, he found it extremely difficult to estimate the value of an intradermal test in the absence of any absolute diagnostic criteria for lymphogranuloma venereum. Combes, Cañizares, and Morris (1942) compared results obtained with Lygranum, mouse brain antigen, and a potent human antigen in the investigation of 89 known cases of lymphogranuloma venereum, as well as a number of other cases. They concluded that results with Lygranum were reliable and that there was less likelihood of false positive or false negative reactions with this antigen than with the mouse brain preparation. False positive results could occur with all three antigens. Robinson and Robinson (1942) did not confirm the finding of Grace and others (1940) that non-specific reactions were rare with Lygranum. Their experience was that, provided sufficient care was taken to avoid confusion between non-specific papules and true reactions, the three antigens were probably equally satisfactory for the intradermal test. Shaffer, Rake, and Grace (1942) compared results with the three 
antigens in cases showing clinical signs of lymphogranulomatous infection. In 106 such cases the Lygranum antigen gave positive results in 96 cases and the mouse brain antigen in 78 cases. Forty-two of the patients were tested with human pus antigen with positive results in 38 cases. They also tested 53 patients, including white and coloured men and women, who were attending a clinic because of venereal infection but who were not suspected of lymphogranulomatous infection. Most of them were suffering from syphilis in some form. Twentynine gave positive tests with the yolk-sac virus antigen and, of these, eighteen showed clinical signs suggestive of lymphogranuloma venereum when re-examined from this point of view. All 29 positive reactors gave positive results to the complement-fixation test performed on blood serum and so did fourteen others with negative intradermal tests, including five who were also found to have clinical evidence of the disease. This seemed to indicate that the serological test was more sensitive than the intradermal test. The findings agreed with those of other workers in obtaining a high percentage of positive intradermal tests among negroes, in the frequency of positive intradermal tests for both chancroid and lymphogranuloma venereum in the same patients, and in the high rate of positive findings among syphilitic patients. Heisel and Stroud (1943) found that the yolk sac antigen provided a fairly reliable test for the disease, but that positive reactions did not always indicate the presence of disease. They thought that a papule $7 \mathrm{~mm}$. in diameter was the smallest size of reaction which justified a positive report on a test with this antigen. Mortara and Greenblatt (1943) found the yolk sac antigen satisfactory and reliable for the intradermal test. It gave neither false positive nor false negative results and reactions from the yolk sac control were slight, if they occurred at all. Knott, Bernstein, Eagle, Billings, Zobel, and Clark (1943) obtained positive intradermal tests with lymphogranuloma venereum antigens in some cases of genital infection without evidence of past or present lymphogranulomatous infection. They therefore questioned the diagnostic specificity of this test in cases of other venereal disease and recommended that results of the test should be interpreted cautiously. Positive reactions did not necessarily establish the diagnosis and negative reactions did not exclude it. Gelperin (1943) found positive intradermal tests with Lygranum antigen in 18.7 per cent. of 192 negro soldiers and $1 \cdot 2$ per cent. of 166 white soldiers. It seemed that, granting the specificity of the test, there was a considerable incidence of latent infection with the virus of lymphogranuloma venereum among negroes. Twenty-nine coloured soldiers who had been in hospital for undiagnosed penile lesions were recalled for examination. Fifteen of them had had painless, discrete, slightly enlarged inguinal glands in addition to the penile lesions at the time of admission to hospital. Nearly half of these patients were found to have positive intradermal tests for lymphogranuloma venereum. Curth (1943) found a high percentage of what she considered to be "non-specific" reactions with the yolk sac antigen which did not occur with human pus antigen. She concluded that the reliability of positive reactions with the yolk sac antigen must be seriously questioned. Heyman (1946) obtained positive intradermal tests with Lygranum in 24 of sixty cases of chancroid (40 per cent.). Packer and Dulaney (1947) tested with Lygranum 343 patients suffering from various infections of the anogenital region. Sixty-one patients with a clinical diagnosis of lymphogranuloma venereum showed positive tests in 33 cases ( 54 per cent.), which was a higher proportion than those with other conditions, including syphilis, chancroid, and granuloma inguinale. Nevertheless, the incidence of positive tests with Lygranum was high in association with the other conditions, a fact which lowered the specific diagnostic value of the test. Many of the patients suffering from other diseases and giving positive tests with Lygranum gave histories of previous genital lesions with buboes, suggesting that the positive tests were due to persistence of response beyond the period of clinical activity of the disease. It was thought that the low sensitivity of the test in cases of clinical lymphogranuloma venereum could probably be explained on the grounds that a considerable interval, varying from 10 to 40 days, often intervened after the onset of the primary lesion before the skin test became positive. Wright, Spencer, and Oppenheim (1947) performed a series of routine intradermal tests on patients without clinical evidence of lymphogranuloma venereum admitted to the medical and surgical wards of the Harlem Hospital. The incidence of positive tests was high in both white and coloured patients, but more so in the latter. They tested 130 children of both races with negative results in all cases. They believed that these findings confirmed the opinion that asymptomatic lymphogranuloma venereum was common in this population. Bedson, Barwell, King, and Bishop (1949) found close parallelism between the result of the Frei test, using yolk sac antigen, and the complement-fixation test in patients with clinical evidence of infection with lymphogranuloma venereum. They accepted a papule of $5 \mathrm{~mm}$. or more in diameter as indicating a positive intradermal test. However, a number of patients suspected of possible infection with lymphogranuloma venereum had strongly positive intradermal tests but little or no antibody in their blood. This was attributed to persistence of reactivity to the intradermal test long after clinical cure, whereas it was to be expected that the antibody titre might fall when the infection became quiescent. Since the effective antigen in the material for intradermal test was the group antigen, it followed that a positive reaction by itself did no more than indicate that infection with a virus of the psittacosislymphogranuloma group had occurred. Whether the infection was recent or not could only be determined by the additional evidence supplied by the complementfixation test. The two tests should, therefore, be used concurrently and a positive intradermal test should not be considered as evidence of active infection with lymphogranuloma venereum, even in a patient whose clinical symptoms and signs suggested the possibility, unless the complement-fixation test was positive with a titre of 1 in 16 or over. Throughout their investigation only one patient showed reaction to the control antigen of normal yolk sac.

The same group of workers (Bedson and others, 1949; 
and Barwell, 1952) prepared more specific antigens by adding dilute hydrochloric acid to saline yolk sac suspensions of the viruses of psittacosis and lymphogranuloma venereum and collecting the supernatant fluid after incubation and prolonged centrifugation. After neutralization the clear supernatant fluid was used undiluted as the test antigen, and these extracts gave reactions which were largely or entirely specific in cases of lymphogranuloma inguinale and of psittacosis.

\section{Interpretation of the Intradermal Test Early in Infection}

It is difficult to determine with certainty the time required for the skin sensitivity to develop, both because of individual variation and because the exact day of infection is often uncertain. Most of the information on this point comes from earlier workers who used antigen obtained from human pus. Costello and Cohen (1941) found that reactions to mouse brain or human pus antigen usually appeared about 2 to 6 weeks after the appearance of the initial lesion. In summarizing the available evidence, Beerman and Ingraham (1950) stated that the best available clinical and experimental information suggested that the reaction became positive in one week to 6 months after the infection was established.

Persistence of the Positive Reaction.-It seems to be generally agreed that once the positive reaction is established it may persist for many years and perhaps during the life of the patient. Hellerström (1929) is quoted as describing persistence after 23 years in one case; and Palmer, Kirsner, and Rodaniche (1942) noted persistence of the reaction as long as 21 years after infection.

There is some evidence that successful treatment early in the course of infection may abolish the reaction. Stein (1940), who successfully treated with sulphanilamide 32 patients suffering from the inguinal lesions of lymphogranuloma venereum, repeated the intradermal tests on five of them 6 to 8 months after the original positive tests had been obtained. The second test was negative in four patients who had been treated before the 90th day of the disease; the fifth patient, whose test remained positive, had had the disease for 3 years. Grace (1941), on the other hand, studied the effect of treatment with sulphonamides on the response to the intradermal test in 37 cases of lymphogranuloma venereum of varying duration but of which six were of less than 3 months. Reversal of the positive test to negative did not occur in any case but there was diminution in the degree of response in one case. In general, however, these patients were less inten- sively treated than those described by Stein (1940). Axelrod (1942) described disappearance of sensitivity to intradermal antigen after prolonged treatment with sulphanilamide in three cases, two of the anorectal form of the disease and one of inguinal adenopathy. Koteen (1945) observed reversal of cutaneous sensitivity in several instances following treatment. Grace, Frank, and Wyse (1952) found that cortisone administered to a patient suffering from lymphogranuloma venereum abolished the reaction to the antigen during the treatment but that reactivity was restored when the cortisone was discontinued. The complement-fixation test for lymphogranuloma venereum was positive throughout the administration of cortisone and showed no change of titre.

Failure to Respond.-It seems that some patients fail to give a positive response to the intradermal test although suffering from the disease. Such failure to respond has been called "anergy". Frei (1938) stated that a negative result should not be taken as proof that the patient had not had lymphogranulomatous infection without considering the possible existence of this phenomenon. In such cases useful information might be given by the intravenous test.

\section{Intravenous Frei Test}

Hellerström (1936) described a febrile response with a rise of temperature of 1 to $1 \frac{1}{2}^{\circ} \mathrm{C}$. 10 or 12 hours after intravenous injection of modified Frei antigen in cases of lymphogranuloma venereum, even when the disease was of many years' duration. This test was also found to be effective with mouse brain antigen by Decker, Cañizares, and Reider (1939), Costello and Cohen (1941), Morris and Cañizares (1942), who found mouse brain antigen more suitable than yolk sac antigen for this purpose, and by Costello and D'Avanzo (1948). Robinson (1945), on the other hand, found the test disappointing and felt that an injection of foreign protein might so often produce febrile response that the method was of limited worth.

\section{Inverted Frei Test}

Frei (1938) also stated that the so-called "inverted test", in which infected material from the suspected case is made into antigen and injected intradermally into a known reactor, might help in cases of difficulty. He advised caution in interpreting the results of this test. Experience had shown that material from diseases unconnected with lymphogranuloma venereum could give positive reactions in patients 
suffering from the disease. Koteen (1945) mentioned the following objections which had been raised against the inverted test:

(1) The infectious agent, or some other such as the tubercle bacillus, might be incompletely inactivated and hence inadvertently introduced into the recipient.

(2) If, by chance, both donor and recipient should have some other infection such as chancroid the test would be positive and would be falsely interpreted as indicating the presence of lymphogranuloma venereum.

\section{Comparison with the Complement-Fixation Test}

There seems to be general agreement that the complement-fixation test for lymphogranuloma venereum is a more sensitive test than the intradermal reaction, although close agreement between the two tests is the rule. Shaffer and others (1942) found that among 146 patients with positive intradermal tests, with or without clinical signs of the disease, only one failed to give a positive complement-fixation test. Grace and Rake (1943) applied both tests to 130 patients with clinical evidence of lymphogranuloma venereum and 72 without such evidence. There were 133 positive reactors of which 97.7 per cent. gave positive reactions to the complement-fixation test and $81 \cdot 2$ per cent. to the Frei test. These percentages were thought to represent the relative degree of sensitivity of the two tests. Blair (1944) performed intradermal tests on 41 patients with strongly positive complement-fixation tests for lymphogranuloma venereum; only 15 (36.6 per cent.) gave positive intradermal tests with papules at least 6 millimetres in diameter. Heyman (1946) used both tests in 25 cases of lymphogranuloma venereum, finding the complement-fixation test to be positive in all and the intradermal test positive in 17 (68 per cent.). Packer and Dulaney (1947) found that of 69 patients with clinical evidence of lymphogranuloma venereum 91 per cent. had positive Lygranum complement-fixation tests, as compared with 54 per cent. with positive Lygranum intradermal tests. Greaves and Taggart (1953) in a study of intradermal tests and complementfixation tests in 104 cases of the disease, were unable to establish a significant relationship between the titre of the complement-fixation test and response to the intradermal test, and this applied to symptomatic and asymptomatic cases. In 62 per cent. of these cases both tests were positive.

To sum up, therefore, the evidence seems to indicate that in the diagnosis of lymphogranuloma venereum the results of intradermal tests and complement-fixation tests run a close parallel. The complement-fixation test appears to be rather more sensitive although in occasional cases of lymphogranuloma venereum, diagnosed as such on clinical grounds, the intradermal test may be positive and the complement-fixation test negative. Both tests give cross reactions with infections due to other viruses of the psittacosis-lymphogranuloma venereum group.

\section{Present InVestigation}

The purpose of the present investigation was to discover the incidence of positive intradermal tests for lymphogranuloma venereum among patients attending the Whitechapel Clinic of the London Hospital and to investigate those patients who gave positive tests with a view to establishing or excluding . the diagnosis of lymphogranuloma venereum.

The antigens employed were prepared from yolk sac culture of the J.H. strain of lymphogranuloma venereum (LGV) virus and was, like Lygranum, a group antigen which might be expected to produce positive tests not only in cases of lymphogranuloma venereum but with infections by other viruses of the group. The technique of preparation was similar to that used in the preparation of Lygranum except that the virus was inactivated by heat instead of with phenol or urea (Bedson and others, 1949). The control was prepared from uninfected yolk sac.

The intention was to apply the test as a routine to all new patients at the time of first attendance at the Clinic during the period of the investigation. The period extended approximately over thirteen months, from November 25, 1954, to December 31, 1955. In the event, not all new patients were submitted to the test; some were excluded because there was no prospect that they could attend to have the test read after 48 hours, but there was no other element of special selection. Some were missed through oversight. Routine practice was to read the test after 48 hours and to accept an inflammatory papule of at least $6 \mathrm{~mm}$. in diameter, together with negative control, as a positive result. Some patients had to be excluded from the investigation because they disappeared from observation before any conclusion could be reached or because they failed to return at an appropriate time for the test to be read. In some cases the test was performed at the second and not the first attendance. In most instances this was due to the fact that the patients presented themselves on a Friday, and Sunday was not a suitable day for reading tests.

Details of the number submitted to routine tests, those excluded through default or other reason, and of the positive and negative results obtained are shown in Table I (overleaf). 
TABLE I

RESULTS OF ROUTINE INTRADERMAL TESTS

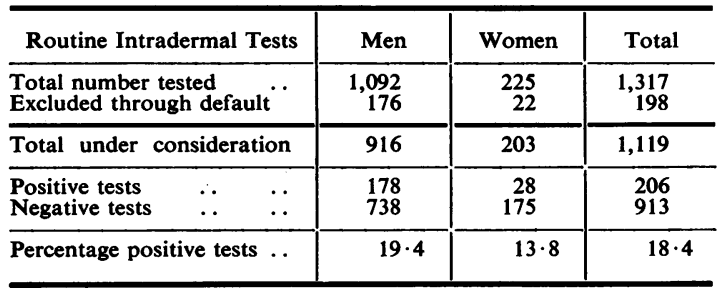

False positive tests, in which positive reactions occurred to both antigen and control, were found in only four cases. These were regarded as negative results to the test.

Serological Tests.-In all cases with positive intradermal tests the blood sera were tested for complement-fixing antibodies to the psittacosis-LGV group antigen. For this purpose a heated yolk sac suspension of psittacosis virus, strain M.O.H. 154, was employed. Potent complement-fixing antigens are rather more readily prepared with this virus and previous experience had not indicated that sera from cases of LGV reacted less well than with similar preparations of the homologous virus. The presence of a positive complement-fixation test with complete fixation at a dilution of 1 in 32 or above was considered to be diagnostic of active lymphogranulomatous infection. In addition to complement-fixation, all patients with positive intradermal (Frei) tests were questioned carefully along the lines shown below, and detailed re-examination was performed to ensure that clinical evidence of lymphogranuloma venereum had not been overlooked (Table II).

\section{TABle II}

\section{LGV QUESTIONNAIRE}

(1) Ever been abroad?

(2) Coitus with coloured girl?

(3) Homosexual exposures?

(4) Coitus with prostitutes in seaports?

(5) Swollen glands in groins?

(6) Sores or lesions on penis?

(7) Pneumonia ?

(8) Increasing constipation or bowel disorder?

(9) Urethral discharge?

(10) Contact with birds ?

On Examination:
(1) Eyes
(2) Lymph nodes
(3) Genitalia
(4) Liver and spleen
(5) Palpation per rectum
(6) Proctoscopy
(7) Urethroscopy

TABLE III

RESULTS OF COMPLEMENT-FIXATION TESTS

\begin{tabular}{|c|c|c|c|}
\hline Results of CFT & Men & Women & Total \\
\hline Positive intradermal tests. . & 178 & 28 & 206 \\
\hline $\begin{array}{l}\text { CFT }+1: 32 \text { or above } \ldots \\
\text { CFT }+ \text { in lesser dilution } . . \\
\text { CFT negative } \ldots\end{array}$ & $\begin{array}{r}18 \\
136 \\
24\end{array}$ & $\begin{array}{r}5 \\
21 \\
2\end{array}$ & $\begin{array}{l}23 \\
157 \\
26\end{array}$ \\
\hline 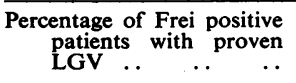 & 10 & 18 & 11 \\
\hline $\begin{array}{l}\text { Percentage of total patients } \\
\text { tested with proven } \\
\text { LGV } \ldots\end{array}$ & $1 \cdot 9$ & $2 \cdot 5$ & 2 \\
\hline
\end{tabular}

The results of complement-fixation tests (CFT) in respect of 178 men and 28 women with positive intradermal tests are shown in Table III.

In the large intermediate group with complementfixation tests positive to titres of 1 in less than 32 , the extent of fixation varied from partial fixation at dilution of 1 in 4 to complete fixation to $1: 16$.

Table IV shows brief details of the findings in ten cases in which there was clinical evidence of lymphogranulomatous infection. Positive intradermal tests led to the correct interpretation of these signs in nine cases. In the remaining case the patient was sent to us with the diagnosis of lymphogranuloma venereum and this was confirmed by positive intradermal and serological tests. In all these cases the sera showed complete fixation to a titre of $1: 32$ or more.

\section{TABLE IV}

CLINICAL EVIDENCE OF LGV IN TEN CASES

\begin{tabular}{|c|c|c|c|c|c|}
\hline \multicolumn{4}{|c|}{ Signs } & Men & Women \\
\hline $\begin{array}{l}\text { Genital lesions } \\
\text { Inguinal adenitis } \\
\text { Proctitis } \\
\text { Rectal stricture } \\
\text { Multiple lesions }\end{array}$ & $\begin{array}{l}\cdots \\
\cdots \\
\cdots \\
\cdots\end{array}$ & $\begin{array}{l}\ldots \\
\cdots \\
\cdots \\
\cdots\end{array}$ & $\begin{array}{l}\cdots \\
\ddot{*} \\
\cdots \\
\cdots\end{array}$ & $\begin{array}{l}2 \\
6 \\
0 \\
0 \\
2\end{array}$ & $\begin{array}{l}0 \\
3 \\
4 \\
1 \\
3\end{array}$ \\
\hline
\end{tabular}

False Positive Results.-In view of the suggestion by several observers that false positive results to intradermal tests may result from the presence of other venereal diseases, especially syphilis and chancroid, it is of interest to note in this series details of other venereal infections from which patients with positive intradermal tests were found to be suffering (Table V, opposite). Only a small proportion of patients with positive intradermal tests were suffering from syphilis or chancroid and, if these diseases do have an effect upon the test, this is unlikely to have been a source of error in this group of cases, 
TABLE V

POSITIVE INTRADERMAL TESTS: ASSOCIATED VENEREAL DISEASES

\begin{tabular}{c|c|c|c|c|c|c}
\hline CFT & $\begin{array}{c}\text { No. of } \\
\text { Patients }\end{array}$ & $\begin{array}{c}\text { Syphi- } \\
\text { lis }\end{array}$ & $\begin{array}{c}\text { Gonor- } \\
\text { rhoea }\end{array}$ & $\begin{array}{c}\text { Non- } \\
\text { gonococcal } \\
\text { urethritis } \\
\text { Trichonomas } \\
\text { Vaginalis }\end{array}$ & $\begin{array}{c}\text { Chan- } \\
\text { croid }\end{array}$ & None \\
\hline $\begin{array}{c}1: 32 \\
\text { or more }\end{array}$ & 23 & 4 & 14 & 5 & 1 & 4 \\
\hline $1 /<32$ & 157 & 14 & 58 & 46 & 2 & 50 \\
\hline Negative & 26 & 2 & 11 & 9 & 2 & 9 \\
\hline
\end{tabular}

Influence of Race.-In view of the comparatively recent influx of coloured people from the West Indies, where lymphogranulomatous infection is much more common than it is in this country, it was of interest to note whether the incidence of positive tests was relatively higher among negroes than white patients. Details are shown in Table VI. The great majority of the negroes concerned were from the West Indies.

TABLE VI

COMPARISON OF WHITES AND NEGROES

\begin{tabular}{|c|c|c|c|c|c|c|c|c|}
\hline \multirow{3}{*}{ Race } & \multirow{3}{*}{ Sex } & \multirow{3}{*}{$\begin{array}{c}\text { Number } \\
\text { Tested }\end{array}$} & \multirow{2}{*}{\multicolumn{2}{|c|}{$\underset{\text { test }+}{\text { Skin }}$}} & \multicolumn{4}{|c|}{ CFT } \\
\hline & & & & & \multicolumn{2}{|c|}{+} & \multirow[b]{2}{*}{ \pm} & \multirow[b]{2}{*}{-} \\
\hline & & & No. & $\%$ & No. & $\%$ & & \\
\hline Whites & $\begin{array}{l}\text { Men } \\
\text { Women }\end{array}$ & $\begin{array}{r}813 \\
\cdot 178\end{array}$ & $\begin{array}{r}132 \\
19 \\
\end{array}$ & $\begin{array}{l}16 \\
11 \\
\end{array}$ & $\begin{array}{r}12 \\
2 \\
\end{array}$ & $1 \cdot 5$ & $\begin{array}{r}102 \\
16 \\
\end{array}$ & $\begin{array}{r}18 \\
1\end{array}$ \\
\hline Negroes & $\begin{array}{l}\text { Men } \\
\text { Women }\end{array}$ & $\begin{array}{l}93 \\
25\end{array}$ & $\begin{array}{r}46 \\
9\end{array}$ & $\begin{array}{l}50 \\
36\end{array}$ & $\begin{array}{l}6 \\
3\end{array}$ & $\begin{array}{l}6 \\
12\end{array}$ & $\begin{array}{r}34 \\
5\end{array}$ & $\begin{array}{l}6 \\
1\end{array}$ \\
\hline
\end{tabular}

Thus, the available information suggests that there is a higher incidence of positive intradermal tests and also of proven lymphogranulomatous infection among negroes in this country than among whites.

Comparison of Antigens. - In view of the fact that most of the recent surveys of this type have been carried out with the commercial antigen Lygranum, a comparison with London Hospital antigen was made by performing tests at the same time with the two antigens on 63 patients. The results are shown in Table VII. There was no discrepancy between results with the two antigens.

TABLE VII

COMPARISON OF LYGRANUM AND LONDON HOSPITAL ANTIGEN

Number of patients tested with both antigens ..

Number excluded through default, an

Number under consideration

Number with tests positive with both antigens.

Number with tests negative with both antigens.

Discrepancies between the tests ..

\section{Discussion}

It has been established that 2 per cent. of patients attending a clinic for venereal diseases in London in a period of 13 months were suffering from active lymphogranulomatous infection which may be presumed to be infectious. Except for routine intradermal tests, all but one of these cases might well have remained undiagnosed. There can be no doubt that routine testing brings these cases to light and it is likely that cases of this disease are remaining undiagnosed in this country at the present time. The criteria for diagnosis were the best available and the validity of the diagnosis cannot be doubted.

In a second and much larger group, positive intradermal tests were associated with a variable amount of complement-fixing antibody in the blood serum. The significance of this finding must remain open to doubt. A patient whose serum gave complete fixation at a dilution of $1: 16$ was clearly producing a considerable quantity of antibody, and the division between $1: 16$ and $1: 32$ is arbitrary and, therefore, unsatisfactory. It is certainly arguable that some of the patients in this intermediate group are suffering from active lymphogranulomatous infection and some of them may be infectious. The third and smallest group with positive intradermal tests and absent complementfixing antibodies may reasonably be supposed to be cases in which infection is of long standing and no longer active.

As one would expect, the relatively small number of negroes showed a proportionately higher incience of proven infection and of doubtful infection. Nevertheless, there was nothing in the histories of the infected white patients to indicate that any appreciable number of them had contracted infection abroad or had had any particular contact with the coloured section of the population in this country. Such as it is, the evidence suggests that recent immigrants have not had any striking effect on the incidence of infectious cases of this disease in the indigenous population.

\section{SUMmary}

(1) Altogether 1,317 patients attending a clinic for venereal diseases for the first time during a period of 13 months from November, 1954, to December, 1955, were submitted to routine intradermal tests with a yolk sac antigen of the virus of lymphogranuloma venereum. Assessment of the results of these tests was possible in 1,119 cases.

(2) Positive intradermal tests were found in 206 cases ( $18 \cdot 4$ per cent.). 
(3) In 23 of these cases ( 2 per cent. of the total) the diagnosis of lymphogranuloma venereum was confirmed by strongly positive complement-fixation tests although only ten of these patients were found to have clinical evidence of the disease. A considerably larger number of patients, namely 157 , showed complement-fixing antibodies in the blood serum but not in sufficient quantity to justify a firm diagnosis of active infection.

(4) The incidence of positive intradermal tests and also of proven lymphogranuloma venereum was relatively higher in the smaller number of negroes examined but there was nothing in the evidence to suggest that the recent influx of coloured population from the West Indies has had a marked effect upon the incidence of this disease in the white population.

(5) The findings suggest that there is an appreciable incidence of undiagnosed lymphogranuloma venereum in the population of the East End of London.

\section{REFERENCES}

Axelrod, S. J. (1942). Amer. J. Syph., 26, 474.

Barwell, C. F. (1952). Brit. J. exp. Path., 33, 268.

Bedson, S. P., Barwell, C. F., King, E. J., and Bishop, L. W. J. (1949). J. clin. Path., 2, 241.

Beerman, H., and İnraham, N. R. (1950). Amer. J. med. Sci., 220, 435.

Binkley, G. W., and Love, W. R. (1938). Arch. Derm. Syph. (Chicago),

Blair, J. E. (1944). J. Immunol, 49, 63.

Brandt, R., and Torpin, R. (1940). Amer. J. Syph., 24, 632.

Combes, F. C., Cañizares, O., and Morris, G. (1942). Arch. Derm. Syph. (Chicago), 46, 264.

Costello, M. J., and Cohen, J. A. (1941). Ibid., 44, 391.

- and D'Avanzo, C. S. (1948). Ibid., 57, 112.

Curth, H. O. (1943). Amer. J. Syph., 27, 47.

Decker, D. A., Cañizares, O., and Reider, R. F. (1939). Arch. Derm. Syph. (Chicago), 40, 397.
Franchi, F. (1939). Gior. ital. Derm. Sif., 80, 369.

Frei, W. (1925). Klin. Wschr., 4, 2148.

(1938). J. Invest. Dermat., 1, 367.

(1939): Ibid., 2, 119.

Gelperin, A. (1943). Amer. J. Syph., 27, 697.

Grace, A. W. (1934). Arch. Derm. Syph. (Chicago), 30, 823.

- (1941). Vener. dis. Inform., $22,349$.

Frank, L., and Wyse, R. J. (1952). Arch. Derm. Syph. (Chicago) $65,348$.

—, and Rake, G. (1943). Ibid., 48, 619.

Rake, G., and Shaffer, M. F. (1940). Proc. Soc. exp. Biol. Med., $45,259$.

- , and Suskind, F. H. (1936a). Arch. Derm. Syph. (Chicago), 33, 853 .

$\longrightarrow$ - (1936b). Ibid., 34, 65 .

Greaves, A. B., and Taggart, S. R. (1953). Amer. J. Syph., 37, 273.

Hanschell, H. M. (1938). Trans. Roy. Soc. Med. Hyg., 31, 578. Heisel, E. B., and Stroud, G. (1943). Arch. Derm. Syph. (Chicago),

Hellerström, S. (1929). Acta. derm.-venereol (Stockh.), suppl. 1

p. 105.
(1936). Acta derm.-venereol (Stockh.), 17, 293.

-, and Wassen, E. (1931). C. R. VIIle Congr. int. Derm. Syph. Copenhague, 1930, p. 1147.

Heyman, A. (1946). Amer. J. Syph., 30, 279.

Knott, L. W., Bernstein, L. H. T., Eagle, H., Billings, T. E., Zobel, R. L., and Clark, E. G. (1943). Amer. J. Syph. 27, 657.

Koteen, H. (1945). Medicine (Baltimore), 24, 1 .

Mortara, F., and Greenblatt, R. B. (1943). Vener. dis. Inform. 24,14 .

Morris, G. E., and Cañizares, O. (1942). Arch. Derm. Syph. (Chicago), 45,953

Packer, H., and Dulaney, A. D. (1947). Amer. J. Syph., 31, 69.

Palmer, W. L., Kirsner, J. B., and Rodaniche, E. C. (1942). J. Amer. med. Ass., 118, 517.

Périn, L., Duperrat, R., and Lafontaine, E. (1946). Ann. Bull. Derm. (Paris), 8 ser., 23 (Abstr. Vener. dis. Inform. 27, 263).

Rake, G., McKee, C. M., and Shaffer, M. F. (1940). Proc. Soc. exp. Biol. (N.Y), 43, 332 .

-, Shaffer, M. F., Grace, A. W., McKee, C. M., and Jones, H. P. (1941). Amer. J. Syph., 25, 687.

Robinson, H. M. (1940). South med. J., 33, 144.

(1945). Quoted by Koteen, 1945.

and Robinson, H. M. Jr. (1942). Arch. Derm. Syph. (Chicago),

45, 112.
Shaffer, M. F., Rake, G., and Grace, A. W. (1942). Amer. J. Syph., 26, 271.

Smith, L. M. (1940). Arch. Derm. Syph. (Chicago), 41, 120.

Stein, R. O. (1940). Amer. J. Syph., 24, 454.

Sulkin, S. E. (1941). J. Amer. med. Ass., 116, 2663.

Wassen, E (1933), C.R. Soc. Biol (Paris), 114, 493.

Wawersig. R. (1939). Derm. Wschr. Leipzig., 109, 1348.

Wright, L. T., Spencer, G. A., and Oppenheim, A. (1947). Amer. J. Syph., 31, 282. 